\title{
Effect of Olive Biomass Ash (OBA) as Cement Replacement in Performance of Polyvinyl Alcohol Engineered Cementitious Composite (ECC- PVA)
}

\author{
Mustafa Maher Al-Tayeb \\ School College of Applied Engineering and Urban Planning, \\ University of Palestine, PO Box 1075, Gaza, Palestine
}

\begin{abstract}
Engineered cementitious composites (ECCs) are a breed of high performance polyvinyl alcohol (PVA) fiber with significant strain-hardening behavior under tension. In this paper, the mechanical performance of ECCs incorporating of olive biomass ash (OBA) is reported. Different ECC-PVA mixes with varying of OBA were used. Emphasis is placed on the influence of OBA content on the key mechanics properties relevant to composite ductility. In the material development, compression stress and single fiber pullout and matrix were performed, followed by fracture analyses to properly select the range of mixture proportion. Subsequent direct tensile tests were employed to assess the strain-hardening behavior of the composite, which exhibited high ductility and strength with the addition of OBA. High ductility is most likely due to enhanced workability and fiber dispersion performance which is attributed to the oxidized grain surface of OBA, as verified by fiber dispersion tests. These results suggest that, the OBA dosage employed in the present study, the contribution of OBA to fiber dispersion outweighs the side-effect of decreased potential for saturated multiple cracking, including a slight increase in matrix fracture toughness and fiber/matrix bond strength.
\end{abstract}

Keywords: Engineered cementitious composites; polyvinyl alcohol fiber; olive biomass ash

DOI: $10.7176 / \mathrm{JEES} / 10-2-07$

Publication date: February $29^{\text {th }} 2020$

\section{Introduction}

Cement consumption is increasing day by day as the main constituent of concrete which is the most widely used construction material. Increased use of cement poses environmental challenge as $5 \%$ of the global anthropogenic $\mathrm{CO} 2$ emission is originated from cement production [1]. While cement production in its beginnings only focused on ordinary Portland cement, later cements with several main constituents were produced by replacing parts of the clinker content by supplementary cementitious materials [2]. Ecological or environmental benefits of alternative supplementary materials include (1) the reduction in the negative effects of producing cement powder, (2) the diversion of non-recycled waste from landfills for useful applications, (3) the reduction in the use of energy for cement production and (4) the corresponding emission of greenhouse gasses [3]. On the other hand many infrastructure deterioration problems and failures can be traced back to the cracking and brittle nature of concrete. It is no wonder that significant research efforts have gone into attempts at enhancing the ductility of concrete materials.

To date, the most effective means of imparting ductility into concrete is by means of fiber reinforcement. Most fiber-reinforced concrete results in enhanced post peak tension-softening behavior under tensile load. This improved toughness is useful in resisting the propagation of cracks into major fractures by energy absorption in the bridging actions of fibers in the fracture process zone [3-23].

The new knowledge has provided an excellent foundation for the design of strain-hardening cementitious composites (engineered cementitious composite, or ECC) with tensile strain capacity in excess of 3\%. Li reported an ECC reinforced with 2\% ultra-high molecular weight polyethylene fibers having a tensile strain capacity of 6 to $8 \%$ [5]. Using very large-sized "compact" tension specimens $(585 \times 490 \times 35 \mathrm{~mm})$, the fracture toughness of this material was determined to be more than $35 \mathrm{~kJ} / \mathrm{m} 2$, approaching that of aluminum alloys.[6,7] Significant damage tolerance of this PE-ECC was demonstrated using a series of uniaxial tension specimens with different notch lengths[8].

Maalej and $\mathrm{Li}$ illustrated the application of such ductile materials in the form of a concrete cover in a reinforced concrete $(\mathrm{R} / \mathrm{C})$ beam [9]. Under 4-point loading, the standard $\mathrm{R} / \mathrm{C}$ beam experienced a crack width in the concrete cover of $1.6 \mathrm{~mm}$ at peak load, while the $\mathrm{R} / \mathrm{C}$ beam with the PE-ECC cover experienced a crack width of $0.2 \mathrm{~mm}$ at a similar load level. This test result suggests the potential use of materials like ECC in enhancing structural durability. ECC is being investigated for use in earthquake-resistant structures [10-12]. Practical applications of ECC, however, are limited by the high cost of ultra-high molecular weight polyethylene fibers. In search of a replacement, polyvinyl alcohol (PVA) fiber has emerged as the most promising alternative. Other lowcost fibers, such as Nylon, low-density polyethylene fiber, and polypropylene fiber, are less suitable due to low tensile strength and low modulus of elasticity. A number of attempts at applying off-the-shelf PVA fiber, however, 
have resulted in composites with significantly lower tensile strain capacities on the order of 0.5 to $1.0 \%$ even if as much as $4 \%$ fiber volume fraction is used $[13,14]$.

The main objective of the work presented herein is to investigate the effects of olive biomass ash (OBA) on compressive strength, single fiber pullout, fracture toughness and direct tensile strength of PVA-ECC at different replacement percentages. In this work, a finely ground OBA (Blaine fineness of $530 \mathrm{~m} 2 / \mathrm{kg}$ ) was used in mortar to partially replace ordinary Portland cement with a replacement amount of 5\%,10\% and 20\% OBA.

The experimental assessment of fracture toughness and crack mouth opening displacement (CMOD) for PVA-ECC with olive oil fuel ash is an added contribution of this study.

\section{Materials and methods}

\subsection{Materials}

ECC is essentially composed of a common mortar matrix and polymer fibers. In this study, a polyvinyl alcohol (PVA) fiber was used as the reinforcing fiber. Type I ordinary Portland cement, silica sand and OBA figure 1 were used as the major ingredients in the matrix.

ECC-PVA specimens were prepared with 5, 10, and $20 \%$ replacements by volume of cement by the OBA (Fig 2); the properties of the samples are summarized in Table 2.

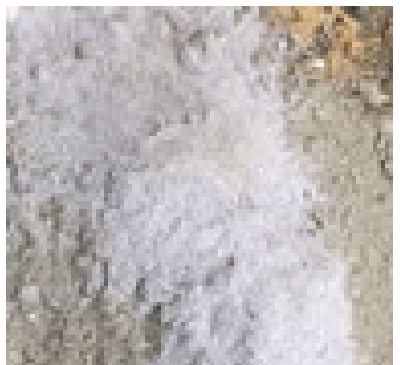

Figure 1: Images of the OBA

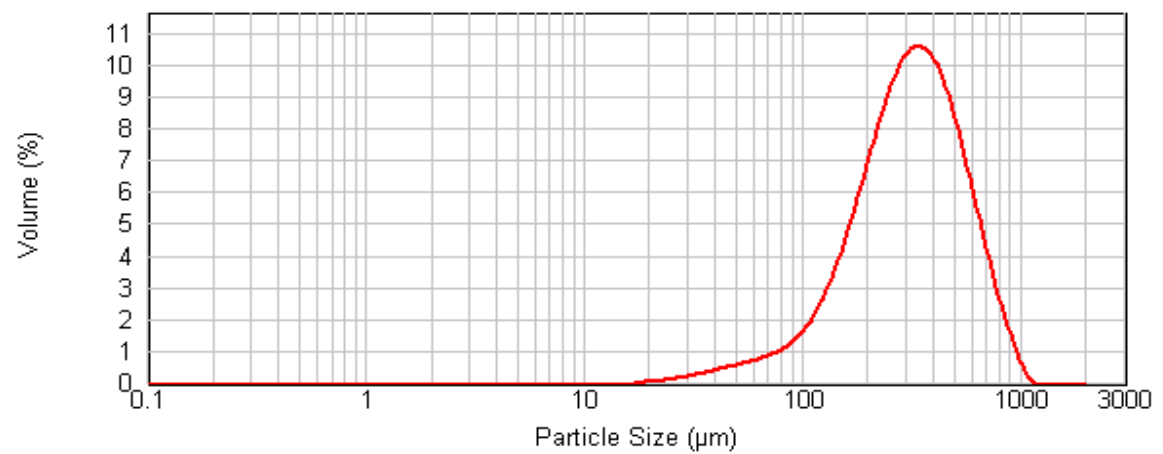

Fig.2: Particle size analysis of OBA.

Table 1: Mixture properties of plain concrete

\begin{tabular}{lllll}
\hline Unit & $\begin{array}{l}\text { Cement } \\
\text { content }\end{array}$ & $\begin{array}{l}\text { Water } \\
\text { content }\end{array}$ & $\begin{array}{l}\text { Fine } \\
\text { aggregate }\end{array}$ & $\begin{array}{l}\text { Fiber } \\
\text { PVA }\end{array}$ \\
\hline Weight $(\mathrm{kg})$ & 580 & 290 & 450 & 25 \\
Volume $\left(\mathrm{m}^{3}\right)$ & 185 & 290 & 170 & 30 \\
\hline
\end{tabular}

Table 2: Mixture properties of

\begin{tabular}{lllcccl}
\hline Unit & $\begin{array}{l}\text { OBA } \\
\text { percentage }\end{array}$ & $\begin{array}{l}\text { Cement } \\
\text { content }\end{array}$ & $\begin{array}{l}\text { Water } \\
\text { content }\end{array}$ & $\begin{array}{l}\text { Fine } \\
\text { aggregate }\end{array}$ & $\begin{array}{l}\text { Fiber } \\
\text { PVA }\end{array}$ & $\begin{array}{l}\text { Olive } \\
\text { oil ash }\end{array}$ \\
\hline Weight $(\mathrm{kg})$ & - & 555 & 280 & 450 & 25 & 28 \\
Volume $\left(\mathrm{m}^{3}\right)$ & $5 \%$ & 176 & 280 & 170 & 30 & 9 \\
Weight $(\mathrm{kg})$ & - & 523 & 260 & 450 & 25 & 57 \\
Volume $\left(\mathrm{m}^{3}\right)$ & $10 \%$ & 166 & 260 & 170 & 30 & 18 \\
Weight $(\mathrm{kg})$ & - & 466 & 230 & 450 & 25 & 113 \\
Volume $\left(\mathrm{m}^{3}\right)$ & $20 \%$ & 148 & 230 & 170 & 30 & 36 \\
\hline
\end{tabular}




\subsection{Tests for obtaining mechanical properties}

The appropriate mixture of ingredient (cement, OBA, PVA fiber, sand, water, and Superplasticizer) loading was determined from preliminary mechanical analyses and mixing tests, as shown in Table 2 . With the aim of attaining increased tensile strength, fracture toughens and enhanced workability,5, 10 and 20\% addition of OBA (in terms of the volume fraction of cement particles) were selected with water-binder ratios of $50 \%$.

\subsubsection{Compression test}

Cube Specimens $50 \mathrm{~mm}$ were used to determine compressive strength according to ASTM C 109 [15]. Testing began at 28 days after casting or when adequate strength had developed.

\subsubsection{Fiber pullout test}

A single fiber pullout test was employed to measure the interfacial properties. Figure 2 illustrates the specimen preparation and experimental setup according [16].
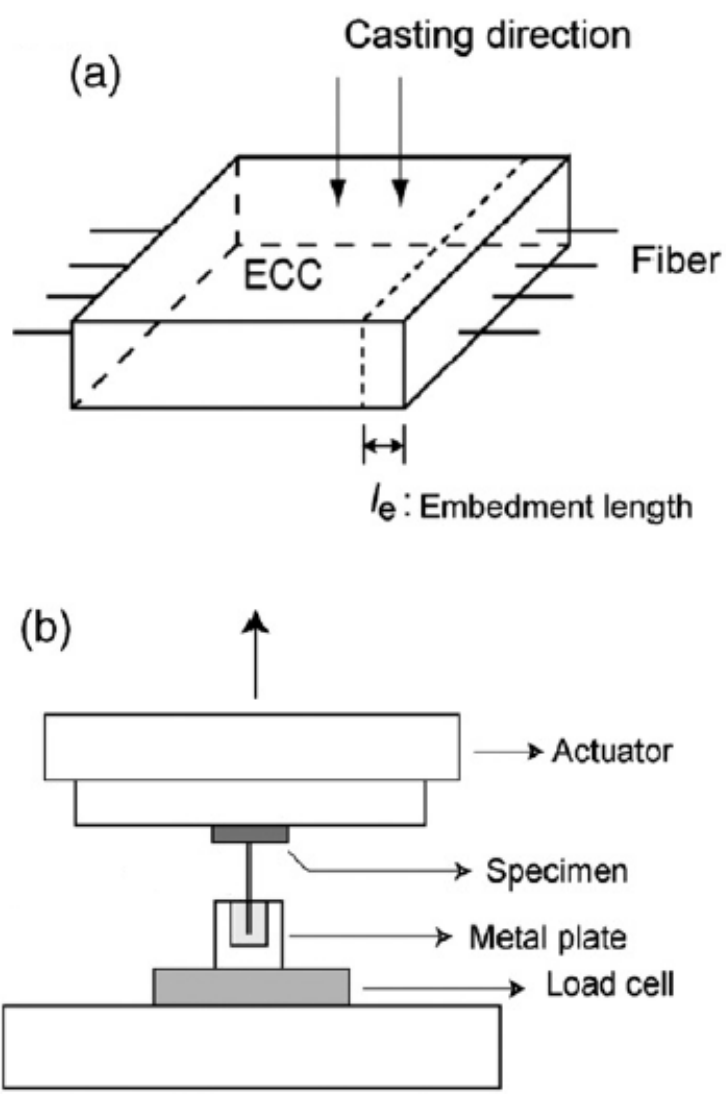

Fig. 3. Single fiber pullout test for (a) the specimen preparation and (b) the test setup [16]

Six specimens were cast together in a small Plexiglas mold. They were demolded at 48 hours, followed by curing in water. The day prior to testing, the specimens were modified to the desired thickness, which corresponds with the fiber embedment length, $1_{\mathrm{e}}$. The fiber embedment length was chosen to be nearly $1.0 \mathrm{~mm}$ in an effort to ensure full debonding. The pullout tests were conducted on the pullout machine with the specimen configuration shown in Figure 2. A 15-N load cell was used to measure the pullout load of the fibers with a displacement rate of $0.3 \mathrm{~mm} / \mathrm{min}$. The displacement was measured as the actuator movement. The fiber-free length was kept at a maximum of $1 \mathrm{~mm}$.

\subsubsection{Fracture test}

For the fracture test, un-notched and notched (using $1.5 \mathrm{~mm}$ wide carbide saw) specimens were prepared, with two notch depths, $25 \mathrm{~mm}$ and $40 \mathrm{~mm}$. Three specimens of each type were made for each ECC-PVA mix. The specimens for fracture test were $50 \mathrm{~mm}$ wide, $75 \mathrm{~mm}$ deep and $350 \mathrm{~mm}$ long, with a loaded span of $300 \mathrm{~mm}$, loaded in a three point bending; the nomenclature of the specimen is shown in Figure 4. Hydraulic testing machine, (Shimadzu, AUTOGRAPH AG-X $100 \mathrm{KN}$ ) used for fracture test. Loading rate was selected so that the maximum load was reached in approximately 5 minutes. The load deflection and CMOD were continuously recorded.

The various fracture toughness parameters analyzed in the present study include stress intensity factor $\left(\mathrm{K}_{\mathrm{IC}}\right)$, Young's modulus $(E)$, critical energy release rate $\left(\mathrm{G}_{\mathrm{IC}}\right)$, fracture energy $\left(\mathrm{G}_{\mathrm{f}}\right)$, and area under load-displacement curve for notched and un-notched specimens ( $\mathrm{A}_{\mathrm{N}}$ and $\mathrm{A}_{\mathrm{UN}}$ respectively).

$\mathrm{K}_{\mathrm{IC}}$ is obtained from [22]: 
$\frac{\left(K_{I c} b \sqrt{d}\right)}{\left(P_{\max }-0.5 W\right)}=\left(\frac{S}{d}\right) f(\alpha)$

Where $\mathrm{P}_{\max }$ and $\mathrm{W}$ are the maximum bending load and self-weight of the beam respectively, and $\mathrm{b}, \mathrm{d}$ and $\mathrm{S}$ are the thickness, depth and span length respectively of the beam. $f(\alpha)$ is the geometry correction for bending load, as expressed by:

$f(\alpha)=\frac{3 \alpha^{\frac{1}{2}}\left[1.99-\alpha(1-\alpha)\left(2.15-3.93 \alpha+2.7 \alpha^{2}\right)\right]}{2(1+2 \alpha)(1-\alpha)^{3 / 2}}$

where $\alpha=\mathrm{a}_{0} / \mathrm{d}$

E of the $50 \mathrm{~mm}$ notched beam was measured from [20]:

$\mathrm{E}=6 \mathrm{~S} \mathrm{a} \mathrm{V}_{1}(\alpha) /\left[\mathrm{C}_{\mathrm{i}} \mathrm{d}^{2} \mathrm{~b}\right]$

$V_{1}(\alpha)=0.76-2.28 \alpha+3.87 \alpha^{2}-2.04 \alpha^{3}+\frac{0.66}{(1-\alpha)^{2}}$

$\mathrm{G}_{\mathrm{IC}}=K_{I C}^{2} / \mathrm{E}$

The RILEM Committee 50-FMC (Fracture Mechanics of Concrete) defined Gf as the total energy absorbed by the material until fracture, and for a/d, it is expressed as [23-25]:

$$
\begin{gathered}
\mathrm{G}_{\mathrm{f}}=\frac{A_{N}+W \delta_{\max }}{\left(d-a_{0}\right) b} \\
A_{N}=\int_{0}^{P_{\max }} \mathrm{P}_{N} d \delta
\end{gathered}
$$

where $\mathrm{W}$ is self-weight of the beam, $\mathrm{P}_{\max }$ is peak load of the notched specimen, and $\delta_{\max }$ is the deflection of notched specimen at $\mathrm{P}_{\max }$.

For the case of un-notched beam (9):

$A_{U N}=\int_{0}^{P_{U N-\max }} \mathrm{P}_{U N} d \delta$

where $\mathrm{P}_{\mathrm{UN}-\max }$ is peak load on the un-notched specimen.

All specimens were demolded at the age of $24 \mathrm{~h}$, and cured in sealed plastic bag at $95 \pm 5 \% \mathrm{RH}, 23 \pm 2{ }^{\circ} \mathrm{C}$ for 7 days. The specimens were then air cured at $50 \pm 5 \% \mathrm{RH}, \quad 23 \pm 2{ }^{\circ} \mathrm{C}$ until the age of 28 days for testing. The complete testing program is detailed below.

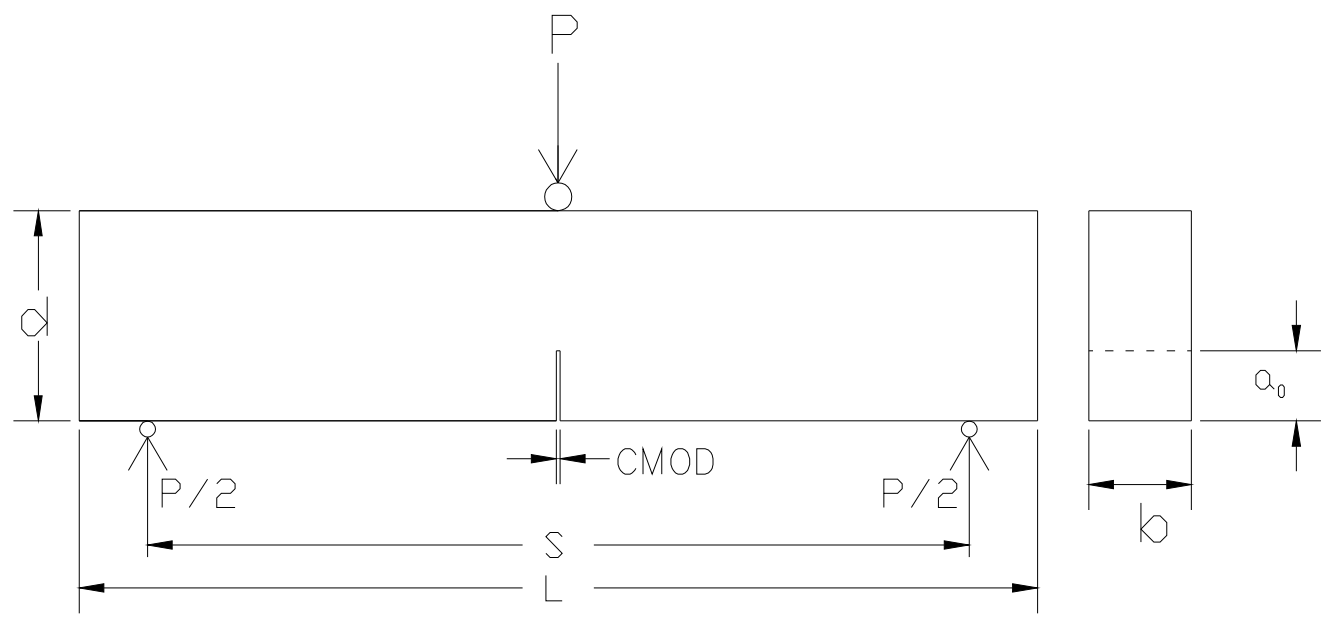

Fig. 4: Nomenclature of the specimen used in the fracture test (d- depth; $b$ - width; $a_{0}-$ notch depth; L-specimen length; S- span length; P- Load). 

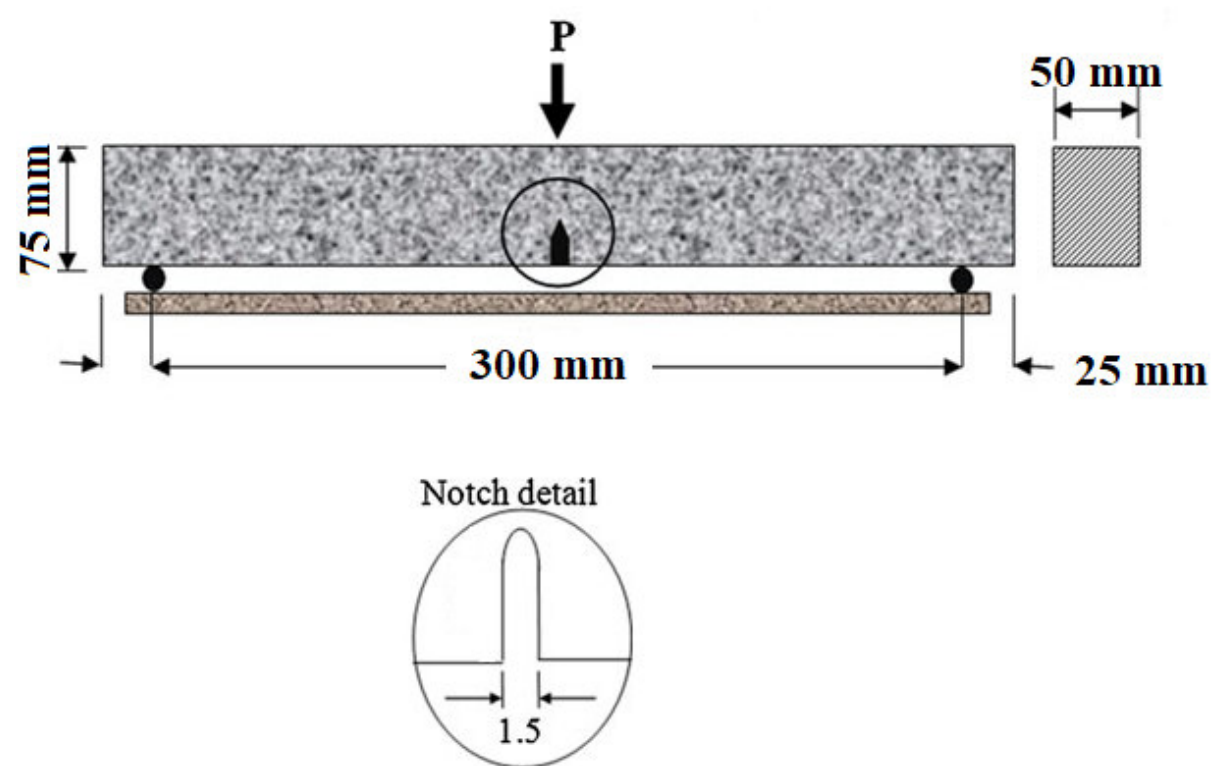

\subsubsection{Direct tensile test}

Fig. 5: fracture test specimen

To verify the strain-hardening behavior of the cast ECC-PVA (both with and without olive fuel ash) specimens, a series of direct tensile tests (three specimens for each ECC mix) were performed. The specimens were loaded with a constant cross head speed $(0.3 \mathrm{~mm} / \mathrm{min})$, and the loading force and elongation were measured. Two linear variable differential transducers (LVDTs) attached to both sides of the center of the tensile specimen with a gage length of $150 \mathrm{~mm}$ in order to monitor the elongation. In addition to the tensile stress-strain curves, the ultimate tensile strength was measured, as was the ultimate tensile strain.

\section{Results and discussion}

\subsection{Flow of Mortar}

One of the advantages when adding OBA into the ECC-PVA is the increase of the workability. The workability test was carried out in accordance with the procedures stated in the ASTM C 1437 standard [17]. Figure 6 shows the workability of the concrete increase with increases OBA. As $20 \%$ of cement volume is replaced by OBA, the workability increase to $15 \%$.

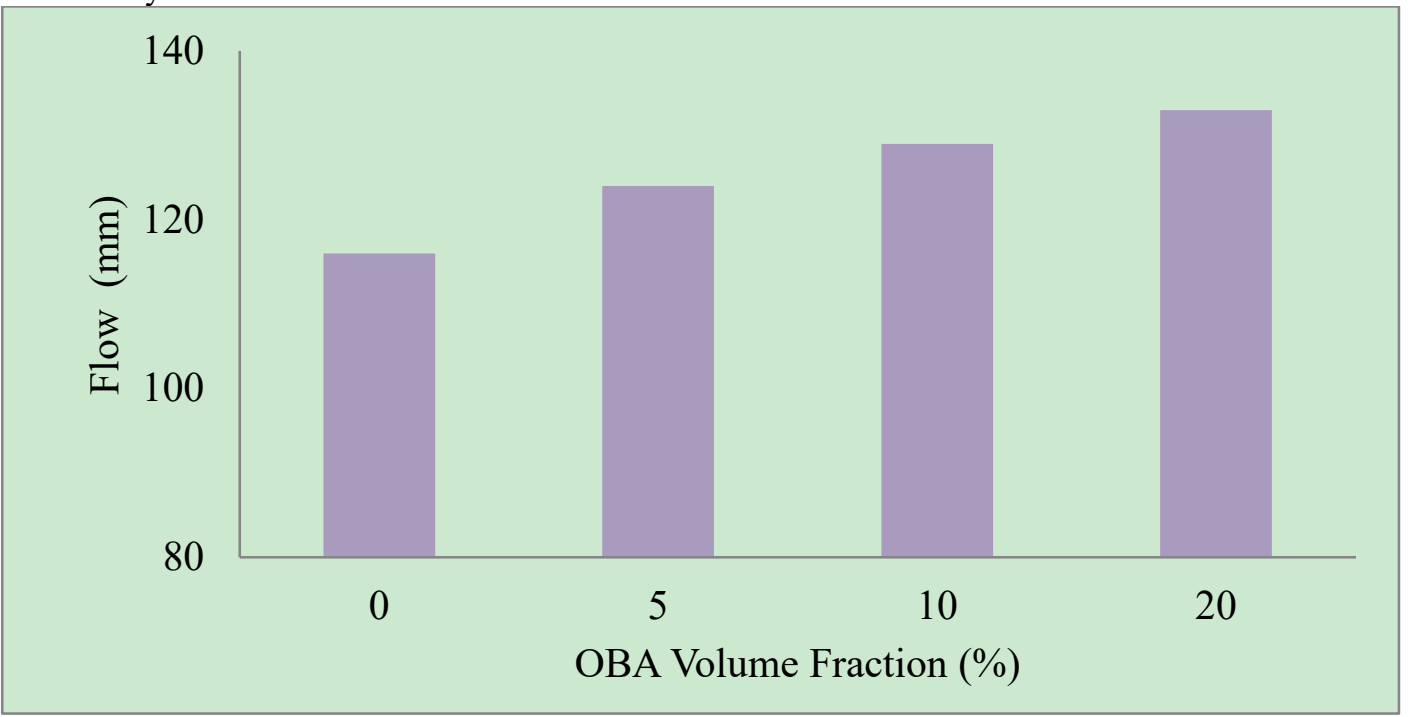

Fig. 6: Effect of cement replacement ratio on flow of ECC-PVA.

\subsection{Compressive strength}

As seen in Fig. 7, the average compressive stress of the control ECC-PVA in 28 days is 36MPa. As the cement is replaced by OBA, the compressive stress increased by 3,8 and $11 \%$ with 5,10 , and $20 \%$ of volumes respectively. High strength of OBA is basically due to the enhanced matrix strength caused by the reduced water-binder ratio and increases the workability. 


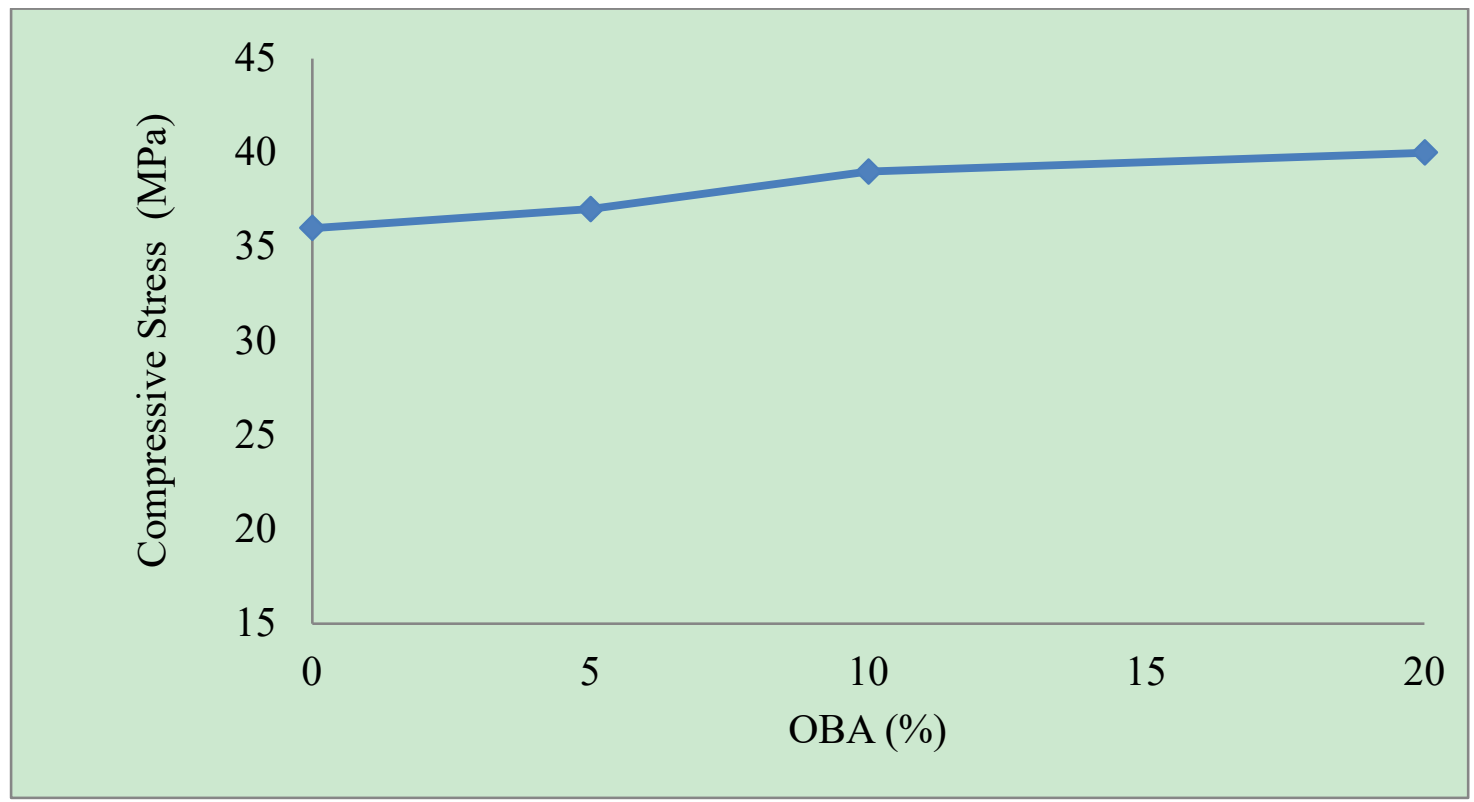

Fig. 7: Compressive stress against volume fraction of OBA.

\subsection{Fiber pullout test}

After debonding, the pullout curve exhibits slip hardening or slip softening depending on the fiber type, fiber/matrix bond strength, and specimen age. Based on this curve, the chemical debonding energy value $G_{d}$, is calculated from the $P_{a}$ to $P_{b}$ difference, as shown in Eq. (10). matrix bond strength, and specimen age. Based on this curve, the chemical debonding energy value $G_{d}$, is calculated from the $P_{a}$ to $P_{b}$ difference, as shown in Eq. (10).

$$
G_{d}=\frac{2\left(P_{a}-P_{b}\right)^{2}}{\pi^{2} E_{f} d_{f}^{3}}
$$

where $\mathrm{E}_{\mathrm{f}}$ is the Young's modulus of the fiber; $\mathrm{P}_{\mathrm{a}}$ is the peak load during the debonding process; $\mathrm{P}_{\mathrm{b}}$ is the peak load during the pullout process; and $d_{f}$ is the fiber diameter [16]. From the $\mathrm{P}_{b}$ value, the frictional bond strength $\tau_{0}$ at the onset of fiber slippage is calculated as follows:

$\tau_{0}=\frac{p_{b}}{\pi l_{e} d_{f}}$

\subsection{Fracture Toughness}

Figure 9 and 10 show the variations in mid-span displacement and CMOD with increase in load, for various cases. In each case, the values are compared with those of the ECC-PVA. The values are compared with those of the control. The results show that mid-span deflection is increased with increase of OBA content. The results show that $\mathrm{KIC}$ increases with increase in the percentage of OBA; this is quite reasonable as KIC depends on the beam geometry and the strength of concrete which tends to increase with the addition of OBA.

On the other hand, replacement of cement by OBA with $5 \%, 10 \%$ and $20 \%$ by volumes creates increase in $\mathrm{A}_{\mathrm{UN}}$ by $5 \%, 11 \%$ and $14 \%$, respectively. As expected, increase in ductility is observed. Figure 10 shows that LoadCMOD values increase by replacement of cement by the OBA. Table 3 shows that the replacement of cement by OBA with $5 \%, 10 \%$ and $20 \%$ by volumes creates increase in CMOD by $1 \%, 16 \%$ and $25 \%$, respectively, which indicates increase in the ductility. 


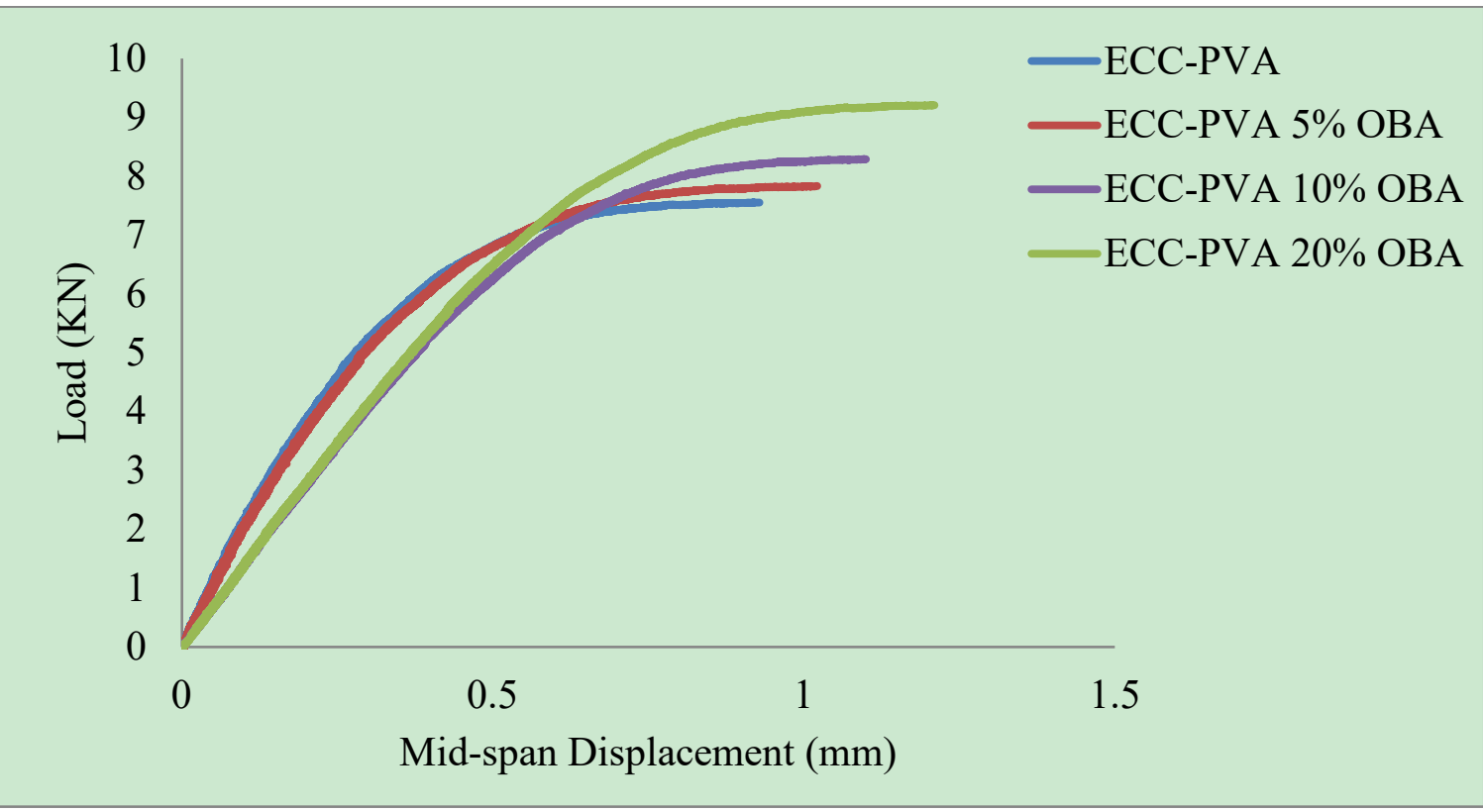

Fig. 9: Load vs mid-span displacement for $50 \mathrm{~mm}$ notch beam of ECC-PVA

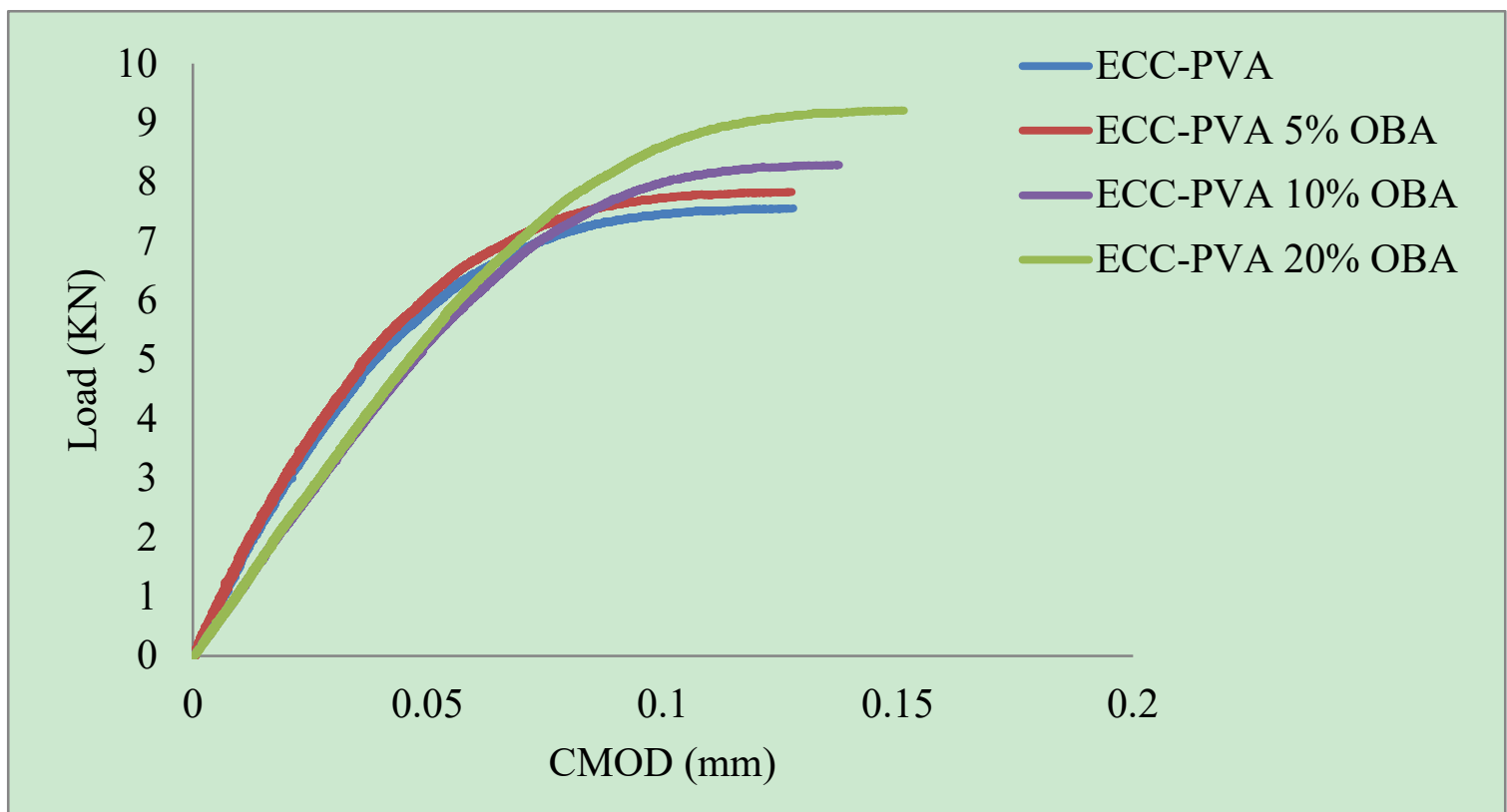

Fig. 10. Load vs CMOD for $50 \mathrm{~mm}$ notch beam of ECC-PVA

Table 3: Experimental and calculated fracture toughness factors with $30 \mathrm{~mm}$ notch

\begin{tabular}{ccccccccccc}
\hline $\begin{array}{c}\text { Type of } \\
\text { mix }\end{array}$ & OBA\% & $\begin{array}{c}\mathrm{P}_{\max } \\
\mathrm{kN}\end{array}$ & $\begin{array}{c}\mathrm{W} \\
\mathrm{N}\end{array}$ & $\begin{array}{c}\mathrm{CMOD} \\
\text { at } \mathrm{P}_{\max } \\
\mathrm{mm}\end{array}$ & $\begin{array}{c}\mathrm{E} \times 10^{10} \\
\mathrm{KN} / \mathrm{mm}\end{array}$ & $\begin{array}{c}\mathrm{C}_{\mathrm{i}} \times 10^{-9} \\
\mathrm{~mm} / \mathrm{KN}\end{array}$ & $\begin{array}{c}\mathrm{Kic} \\
\mathrm{MPa} \sqrt{\mathrm{m}}\end{array}$ & $\begin{array}{c}\mathrm{G}_{\mathrm{ic}} \\
\mathrm{N} / \mathrm{m}\end{array}$ & $\begin{array}{c}\mathrm{A}_{\mathrm{UN}} \\
\mathrm{KN} \times \\
\mathrm{mm}\end{array}$ & $\begin{array}{c}\mathrm{A}_{\mathrm{N}} \\
\mathrm{KN} \times \mathrm{mm}\end{array}$ \\
\hline ECC- & $0 \%$ & 7.4 & 33 & 0.13 & 2.1 & 18.7 & 1.7 & 433 & 3.5 & 2.6 \\
PVA & $5 \%$ & 7.9 & 33 & 0.13 & 2.2 & 19.5 & 1.9 & 447 & 3.7 & 2.7 \\
with & $10 \%$ & 8.3 & 33 & 0.14 & 2.2 & 20.6 & 2.3 & 461 & 3.9 & 3.1 \\
OBA & $20 \%$ & 9.5 & 33 & 0.15 & 2.3 & 20.3 & 2.8 & 460 & 4.0 & 3.2 \\
\hline
\end{tabular}




\begin{tabular}{|c|c|c|c|c|c|c|c|}
\hline \multirow[t]{3}{*}{ Type of mix } & \multirow[t]{3}{*}{$\mathrm{OBA} \%$} & \multirow[t]{3}{*}{$\mathrm{a} / \mathrm{d}$} & \multirow{3}{*}{$\begin{array}{c}\mathrm{P}_{\max } \\
\mathrm{kN}\end{array}$} & \multirow{3}{*}{$\begin{array}{l}\mathrm{W} \\
\mathrm{N}\end{array}$} & \multirow{3}{*}{$\begin{array}{c}\mathrm{A}_{\mathrm{N}} \\
\mathrm{N} \text { m }\end{array}$} & \multirow{3}{*}{$\begin{array}{l}\delta_{\max } \\
\mathrm{mm}\end{array}$} & \multirow{3}{*}{$\begin{array}{c}\mathrm{G}_{\mathrm{f}} \\
\mathrm{N} / \mathrm{m}\end{array}$} \\
\hline & & & & & & & \\
\hline & & & & & & & \\
\hline \multirow{4}{*}{ ECC-PVA } & $0 \%$ & 0.5 & 6.9 & 33 & 0.51 & 0.90 & 103 \\
\hline & $5 \%$ & 0.5 & 7.1 & 33 & 0.54 & 0.10 & 112 \\
\hline & $10 \%$ & 0.5 & 7.3 & 33 & 0.59 & 0.11 & 124 \\
\hline & $20 \%$ & 0.5 & 8.0 & 33 & 0.58 & 0.10 & 135 \\
\hline
\end{tabular}

On the other hand the results indicate that despite slightly increase in strength, a $5 \%$ replacement of cement by OBA yields slight increase $(3 \%)$ in $\mathrm{G}_{\mathrm{IC}}$ compared to the control ECC-PVA, rendering the mixture relatively ductile. Also, a 10\% replacement of cement by the OBA causes $6 \%$ increase in $\mathrm{G}_{\mathrm{IC}}$, indicating further increase in ductility. However, it is interesting to note that addition of $20 \%$ OBA makes appreciable decrease in GIC.

\subsection{Direct tensile tests}

Direct tensile tests were performed on cast specimens of the ECC in order to confirm the ductile strain-hardening performance of the hardened composite. All specimens exhibit apparent multiple cracking patterns accompanying pseudo strain-hardening behavior with strain capacities ranging from $2.2 \%$ to nearly $2.6 \%$. This ductility remains much higher than that in normal concrete and conventional FRC composites. The addition of OBA leads to higher tensile strain capacity accompanied by greater composite strength than those of the composite without OBA. High strength of OBA-ECC is basically due to the enhanced matrix strength caused by the reduced water-binder ratio.

\section{Conclusion}

An ECC mixture proportion with satisfactory tensile behavior was developed by employing OBA with the use of a mechanical analysis. In the material development process, a series of tests were performed to obtain the fibermatrix interfacial properties and matrix fracture properties required for analyzing the fiber bridging behavior, followed by demonstration tests including direct tensile, and fiber pullout tests. The following conclusions can be drawn from the experimental and analytical results:

1. An optimized range of the OBA-ECC mixture proportion was obtained. This was determined based on the mechanical principle. A mechanical analysis was initially performed to select the appropriate OBA ratio based on the results from single fiber pullout tests and matrix fracture tests.

2. The fracture properties of concrete containing $5 \%, 10 \%$, and $20 \%$ by volumes, of OBA (cement replacement), were analyzed using three-point bending test. The study of fracture characteristics of ECCPVA with OBA as cement replacement, were unique features of this work. High precision machinery was facilitated for the experiments.

3. A mechanical analysis was initially performed to select the appropriate water-binder ratio based on the results from single fiber pullout tests and matrix fracture tests. The basic matrix proportion range was then determined based on fiber bridging analysis results and workability considerations.

4. Both ductility and tensile strength of the OBA-ECC were measured to be significantly higher than these values for the ECC without OBA.

\section{Reference}

[1] Humphreys K, Mahasenan M. Toward a sustainable cement industry. Substudy 8, climate change. World Business Council for Sustainable Development; 2002.

[2] Ali MB, Saidur R, Hossain MS. A review on emission analysis in cement industries. Renew Sustain Energy Rev 2011;15:2252-61.

[3] Ramos, Telma, Ana Mafalda Matos, and Joana Sousa-Coutinho. "Mortar with wood waste ash: Mechanical strength carbonation resistance and ASR expansion." Construction and Building Materials 49 (2013): 343351.

[4] $\mathrm{Li}$, Victor $\mathrm{C}$., et al. "Interface tailoring for strain-hardening polyvinyl alcohol-engineered cementitious composite (PVA-ECC)." Materials Journal 99.5 (2002): 463-472.

[5] Li, V. C., "Engineered Cementitious Composites-Tailored Composites Through Micromechanical Modeling," Fiber Reinforced Concrete: Present and the Future, N. Banthia, A. Bentur, and A. Mufti, eds., Canadian Society for Civil Engineering, Montreal, 1998, pp. 64-97.

[6] 8. Li, V. C., and Hashida, T., "Engineering Ductile Fracture in Brittle Matrix Composites," Journal of Materials Science Letters, V. 12, 1993, pp. 898-901.

[7] 9. Maalej, M.; Li, V. C.; and Hashida, T., "Effect of Fiber Rupture on Tensile Properties of Short Fiber Composites,” ASCE Journal of Engineering Mechanics, V. 121, No. 8, 1995, pp. 903-913. 
[8] 10. Li, V. C., "Damage Tolerance of Engineered Cementitious Composites," Advances in Fracture Research, Proceedings, 9th ICF Conference on Fracture, Sydney, Australia, B. L. Karihaloo; Y. W. Mai; M. I. Ripley; and R. O. Ritchie, eds., Pub. Pergamon, UK, 1997, pp. 619-630.

[9] 11. Maalej, M., and Li, V. C., "Introduction of Strain Hardening Engineered Cementitious Composites in the Design of Reinforced Concrete Flexural Members for Improved Durability," ACI Structural Journal, V. 92, No. 2, Mar.-Apr. 1995, pp. 167-176.

[10] 12. Fischer, G., and Li, V. C., "Structural Composites with ECC," The 6th ASCCS International Conference: Steel-Concrete Composite Structures, Los Angeles, Calif., Mar. 2000, pp. 1001-1009.

[11] 13. Parra-Montesinos, G., and Wight, J. K., "Seismic Response of Exterior RC Column-to-Steel Beam Connections," ASCE Journal of Structural Engineering, V. 126, No. 10, Oct. 2000, pp. 1113-1121.

[12] 14. Fukuyama, H.; Sato, Y.; Li, V. C.; Matsuzaki, Y.; and Mihashi, H., "Ductile Engineered Cementitious Composite Elements for Seismic Structural Applications," Proceedings of the 12th World Conference of Earthquake Engineering, 2000, No. 1672.

[13] 15. Shao, Y., and Shah, S. P., "Mechanical Properties of PVA Fiber Reinforced Cement Composites Fabricated by Extrusion Processing," ACI Materials Journal, V. 94, No. 6, Nov.-Dec. 1997, pp. 555-564.

[14] 16. Kanda, T., and Li, V. C., "Interface Property and Apparent Strength of a High Strength Hydrophilic Fiber in Cement Matrix," ASCE Journal of Materials in Civil Engineering, V. 10, No. 1, 1998, pp. 5-13.

[15] American Society for Testing and Materials (ASTM) C109M, C109M Standard Test Method for Compressive Strength of Hydraulic Cement Mortars, Annual Book of ASTM Standards, Pennsylvania (2001).

[16] Kim, Jin-Keun, et al. "Tensile and fiber dispersion performance of ECC (engineered cementitious composites) produced with ground granulated blast furnace slag." Cement and Concrete Research 37.7 (2007): 1096-1105.

[17] American Society for Testing and Materials (ASTM) C 1437, Standard Test Method for Flow of Hydraulic Cement Mortar, Annual Book of ASTM Standards, Pennsylvania (2001).

[18] Hasan, Hayder Alaa, M. Neaz Sheikh, and Muhammad NS Hadi. "Maximum axial load carrying capacity of Fibre Reinforced-Polymer (FRP) bar reinforced concrete columns under axial compression." Structures. Vol. 19. Elsevier, 2019.

[19] Mousavi, Tohid, and Erfan Shafei. "Impact response of hybrid FRP-steel reinforced concrete slabs." Structures. Vol. 19. Elsevier, 2019.

[20] Jumaa, Ghazi Bahroz, and Ali Ramadhan Yousif. "Numerical modeling of size effect in shear strength of FRP-reinforced concrete beams." Structures. Vol. 20. Elsevier, 2019.

[21] Ayoub , M. ; Nasr , H. ; Negim , S. ; Darweesh, H. Synthesis, characterization, and cement application of vinyl acetate water-soluble graft polymers. Polym.-Plast. Technol. Eng. 2005 , 44(2), 305-319.

[22] Dweik , H.S. ; Ziara , M.M. ; Hadidoun , M.S. Enhancing concrete strength and thermal insulation using thermoset plastic waste. Int. J. Polym. Mater. 2008 , 57(7), 635-656.

[23] Perevozchikov , A. ; Yakovlev , G. ; Kodolov , V. Polyethylene foam waste utilization for light-weight concrete production. Int. J. Polym. Mater. 2000, 47(1), 7-17.

[24] Al-Tayeb, Mustafa Maher, et al. "Effect of partial replacements of sand and cement by waste rubber on the fracture characteristics of concrete." Polymer-Plastics Technology and Engineering 51.6 (2012): 583-589.

[25] Al-Tayeb, Mustafa Maher, et al. "Impact resistance of concrete with partial replacements of sand and cement by waste rubber." Polymer-Plastics Technology and Engineering 51.12 (2012): 1230-1236. 